it would be for the doctor. The doctor's bills would now no longer be questioned, for "particulars" would be given in full-they would simply be fees for extraordinary visits. He would also know, as a general rule, what was his day's work by breakfast time; and, this work being done, he would not only be comparatively free, but would have the very great comfort of feeling so ; and when a summons did come he would be sure that it was not a mere whim of some inconsiderate or fanciful patient : whims and fancies would at least be reduced to a minimum if the doctor's house were surrounded by a cordon which could only be broken by a golden key. I anticipate, farther, that the relation between the doctor and the family would be immensely improved, and that he would no longer be a "servant" and his patients "slaves"; their relation to each other would be that of "friends", and it would be much less liable to disturbance. People would, no doubt, be more careful, and take a longer time in making their choice of a doctor, but, having made it, would be less likely to change.

Turn, now, to the condition of the patients: their grievances have vanished into thin air. Their interest has been put first, and it coincides so entirely with that of the doctor that there is no room left for suspicions and misunderstandings. Again, under such a system, clubdoctors would cease to exist, for the annual sum for ordinary work would obviously admit of graduation far more easily than is possible in charging per visit or even per bottle.

Club doctors-at least men with duties such as are now expectedwould not be wanted; possibly such officers might be appointed, but their duties would be different. The payment would still be small, but the service demanded would not be great: their duties would be to look after the interests of the club, to protect it against the admission of unhealthy members, and against ill-founded declarations against the funds of sick members, and to perform other such general and highly honourable service. The power of combination for such a purpose as to provide medical aid may be inferred from the extraordinary results obtained by two or three of the provident dispensaries, in which the benefiting members contribute so small a sum as Id. a week, or 4 s. 4 d. a year. From the fortieth report of the Derby Provident Dispensary, it appears that mem. bers of this class contribute more than $\mathrm{r}$ Iooo a year. If so much can be done by pennies, how much more might be done if arrangements on a better plan could be marle for the twopenny, threepenny, etc., class? Let the provident, or, as I would rather say, the preventive principle, have full play, and imagination could hardly say too much as to what misht be achieverl.

Forty years arro, Mr. Jones of Derby and Mr. Smith of Southam had the sagacity to perceive and the benevolence and courage to make the experiment with the least productive element; and, though the result is not such that $\mathrm{I}$ can conscientiously recommend you, now in $\mathrm{I} 87 \mathrm{I}$, io adopt their plan, it is abundantly sufficient to show the soundness of the principle upon which they acted, and further to prove that it needs only that we trust those principles more thoroughly to realise still greater results-greater in every way, both commercially, and, more important still, crreater in the sense of being more thoroughly efficient and iree from certain professional faults which have, no doubt, been a prin. cipal cause why provident dispensaries, even where most successful (as at Coventry, Northampton, and Derby), have never attained to anything more than mediocrity. All honour, however, be to Mr. Jones and to Mr. Smith for having done so much ; anything that we do will be by standing upon their shoulders.

I see no reason to doubt that, in a well-managed local association, five or six medical men working together under a well constituted representative board of management, the working classes might provide themselves with thoroughly efficient medical aid, including even payment for their admission when necessary into hospitals, and including many other things which at present are beyond their reach. Those arrangements would bring relief more or less directly to the whole profession, but primarily to those who are connected with hospitals. A better sysiem of attendance for the working classes at home would relieve these noble institutions very much of the routine work which overwhelms them; and if arrangements were made for members of such associations to pay for admission, hospitals would be relieved financially - they would hecome gradually more or less self-supporting. When this comes to pass, but not till then-that is, when patients are admitted on their own right by payment-can I look with anything but jealousy upon the proposal to give salaries to any portion of the medical staff. Meanwhile, relieve us of all work that ought to be done by the parish - of all work that might be done outside the hospital; put us in a worition to attend exclusively to urrent cases, and we will ask no more. This will require from the public no little sum of money. We inave ourelves spent recently some 620.000 in altering (would that it had been in rebuilding) our Hospital. When I ask for this as a necesary expenditure, I do in effect ask for a sum which, if capitalised, would have produced $£$ Soo a year. The medical staff might have received this for their services with a clear conscience ; but, I ask my colleagues, had the Hospital remained as it was ten years ago, with this difference, that we were now in receipt of $£ 200$ a year each for our services, should we, as professional men, have been in as good a position as at present? I repeat, all that honorary medical officers ought to ask at present in return for their services is protection against the admission of improper cases, and that every facility possible should be afforded to enable them to do their work thoroughly well. As to what I will call first-class practice, independent of that in connexion with hospitals, I would simply ask that the physician or surgeon be left to take care of himself, and that attention be directed entirely, or at least primarily, to the improvement of the character of the service. A consultation at present is a very unsatisfactory proceeding to all partiès. It lacks that first element of satisfaction, in that no care is taken to secure that the second opinion shall be formed independently. On the contrary, the first thing done is for the doctors to talk the case over privately: this makes it impossible for the second to form a perfectly independent opinion, and this mars the whole proceeding. That which I should wish to do, and to be compelled to do in any case wherein my opinion was desired, is to examine the case thoroughly for myself. Thi, done, I am prepared to meet the family doctor and to consult with hims and then the patient obtains the benefit of two opinions; and two heads are better than one. As thing;, however, are at present, the family doctor paid per visit and per bottle, and the doctor called in paid in the same way, this freedom of action is almost impossible ; but, if the family doctor were paid for annum, the difficulty would be lessened, if not entirely removed.

Did time permit, I might easily show the effect of such an arrangement upon counter practice, and on quackery, and on special practice, which is often but a disguised form of quackery ; but I have already detained you longer than I ought to have done. It remains, therefore, for me to thank you for your patient and indulgent attention, and to conclude by giving you a most cordial welcome to Derby. By the kindness of the Weekly Board of Management, we meet in this room. I regret that time will not now allow me to show you over the Hospital; but be assured that at any time when business or inclination may bring you to Derby, we, the honorary medical staff, shall be prepared to rereceive you as brethren, and to show you what has been done; and, for myself at least, I will add, not merely to act as your guide, but to look for instruction from your visit. If any should think that the views herein so imperfectly set forth are worthy of further consideration, I shall count it no less my privilege than my duty to confer with them further, and to give any assistance in my power to towards putting them into practice. I shall also ever receive with respectful attention all remarks (pub. licly or privately expressed) from those who differ from me; whilst to those who agree with me I will only offer a word of caution against being too sanguine of speedy success or of personal gain. Evils such as I have enumerated can only be removed very gradually; work such as remains to be done must be encountered with a single eye, and, by God's help, in the spirit of the "Iron Duke", who used to say in the face of every difficulty, "I know nothing of difficulties, but that they are things to be overcome".

\section{ON THE THEORY OF DISINFECTANTS.*}

\section{BY T. P. BLUNT, M.A., F.C.S.}

THE light which has recently been thrown upon the nature of contagion and infection by the labours of Pasteur and others, the results of which have been ably summarised by the President of the British Association in his late inaugural address at Liverpool, seems to point the way to clearer and more comprehensive views than those commonly entertained at present regarding the operation of the substances known as disinfectants.

These may be divided into two classes: $\mathbf{I}$. Those which act by the oxidation and total destruction of the virus contained in infected matters, together with the foul gases which usually accompany it, and which are, in fact, Nature's danger-signals of its presence. 2. Those substances which do not possess the active chemical properties of the first class, yet are proved by experience to have a similar power of arresting and checking the spread of infection. The latter are, for the most part, the more ancient and popular, having apparently in some cases been suggested by a just but unreasoning instinct. Thus we find that the use of sulphurous acid, as evolved from burning sulphur, dates even from IIomeric days; while the burning of pitcl and

* Read before the annual meeting of the Shropshire Scientific Branch. 
aromatic gums for disinfectant purposes has an origin at least equally remote.

An attempt will be made, in the course of the observations which follow, to bring the operation of the large majority of the latter class under a general law which shall furnish us with an explanation of their true character. This is especially desirable, since it is to be feared that, for want of such an explanation, many good and valuable disinfectants have been condemned by chemists, on theoretical grounds, as mere deodorisers-not assailing the virus of infected substances, but rather masking their poisonous character by precipitating their offensive gases. An objection to this view at once meets us, in the utter disproportion between the volume of the gases to be fixed and the quan. tity of salt practically found sufficient for the object required, while it breaks down altogether when applied to such disinfectants as the new "chloralum" or chloride of aluminium of Mr. John Gamgee, or the well known carbolic acid. Before endeavouring to supply a more probable theory, it may be well to remind you that the researches already mentioned have established the fact that contagion and putrefaction, if not actually identical, are processes so closely allied that they require exactly similar conditions; the latter appearing to consist of a kind of disease propagated from particle to particle of a decomposing substance, and ending in its entire destruction. Hence it may be inferred with perfect safety, that any agent which arrests putrefaction is capable also of abolishing the properties of contagion and infection.

This conclusion at once puts into our hands a valuable instrument of research ; for while it is difficult, and often impossible, to investigate directly the disinfectant action of a substance, the inquiry being surrounded by innumerable sources of error, the properties of an antiseptic are perfectly well defined, and open to the clearest demonstra. tion. Thus, in the case of the two bodies mentioned above, carbolic acid and chloride of aluminium, the antiseptic action of the first is well known, and has long been usefully applied; while that of the latter is maintained in the most positive manner by its introducer, Mr. John Gamgee, who certainly brings forward overwhelming proof of it in his recorded experiments upon meat and fish; and hence, on the grounds given, we are justified in regarding these substances as good and useful disinfectants. It may be stated, in passing, that the deodorising power which these and other similar bodies possess is probably due to their antiseptic action; the offensive gases of decomposition being sooner lost by diffusion, and their fresh production being entirely suspended.

Let us now proceed to a consideration of the origin of the remarkable properties which we have described. This appears to have been traced with some degree of probability, in the case of carbolic acid, by Dr. Joseph Hirsch, the writer of an article which appeared in the Chemical Neivs about the end of February 1869. He advances the bold and ingenious speculation, that the disinfecting action of that substance depends upon its power of coagulating albumen. He supposes that the acid finds its way into the minute organisms, which propagate disease by diffusion through their investing membrane; that it coagulates the albumen which they, in common with all germinal matter, contain as a necessary constituent ; and thus practically destroys their vitality as perfectly as immersion in boiling water terminates that of an egg.

In order to test the accuracy of the view thus enunciated, I selected a substance of which the albumen-coagulating power was well known, and examined it with regard to its antiseptic, and therefore disinfectant, properties. The substance chosen was nitro-muriatic acid, which has long been in use as a test for albumen in urine. The experiments were conducted as follows.

a. Two samples of fresh healthy urine, passed at the same time, each measuring about one ounce, were placed side by side. To one of them six drops of strong nitro-muriatic acid were added. In a few days, the unacidified specimen was covered with a thick crust of mould; while that to which the acid had been added was unaltered, except by a slight darkening of colour and deposition of crystals of uric acid.

$b$. Some fresh meat was pounded into an emulsion with water-the whole divided into two equal portions of about six drachms each. To one of them six drops of strong nitro-muriatic acid were added, as in the former case. In a day or two, the unacidified sample was quite putrid and offensive; while that to which the acid had been added retained the smell of fresh meat, and continues to do so still, after the lapse of nearly a month.

I now proceeded to test sorie of the salts commonly used as disinfectants, with respect to their possession of this power of coagulating albumen. The examination was conducted thus. One part of the salt to be tested was dissolved in one thousand parts of distilled water, and the solution was mixed thoroughly with the fresh white of egg. The salts examined were iron-alum, sesquichloride of iron, common alum, chloride of zinc, and nitrate of lead. Coagulation fol- lowed immediately in every instance. In one or two cases, the dilution was carried much further-one part of the salt to three or four thousand of water. Here, too, coagulation followed in one or two seconds.

It may be remarked, in passing, that the hæmostatic action of the iron-salts is probably to be attributed in great measure to this faculty of coagulating albumen, exercised upon the serum of the blood.

The attempt to obtain similar results from the sulphites entirely failed. They appeared, indeed, to retard coagulation by other reagents. The coagulating power of sulphurous acid was faint and ill defined.

If we review the evidence now before us, we shall find that it stands thus.

We start with two assumptions-the first justified by recent research, the second borne out by analogy ; viz., that infection results from the transference and development of minute germs; and that these germs contain albuminous matter as a necessary constituent, the coagulation of which terminates their existence. Upon these assumptions we frame our major premiss-that "all coagulators of albumen are disinfectants"; and, having arrived at this result by a process of pure reasoning, we proceed to prove its truth by experiments upon the antiseptic, and so upon the disinfectant, properties of a well known albumen-coagulator. Having thus established our fundamental proposition, we produce experimental proof of our minor premiss-that "nearly all the substances to which popular experience has assigned the property of arresting the spread of infectious diseases, where that power is at present unexplained, are coagulators of albumen." The conclusion then necessarily follows, that these substances are disinfectants; and thus a vindication of their efficiency is furnished in those cases where it has been called in question by chemists on the ground that no sufficient explanation of their action had been offered.

The above conclusion does not apply to sulphurous acid and the sulphites. In their case, we must probably look for some more remote physiological effect upon germinal existence.

Note on the Use of Hydrochloric Aitd as an Antiseptic.

It is probable that hydrochloric acid, which shares the properties attributed to nitrohydrochloric acid in the foregoing remarks, will be found to be a valuable preservative of animal food. A piece of meat, immersed for fifteen minutes in a mixture of one part of the acid to three of water, remained entirely free from putrefactive change after nearly a fortnight, though the action of the acid was not sufficiently powerful to prevent the appearance of a small quantity of mould. The meat was then immersed in a dilute solution of carbonate of soda, and the superficially absorbed acid was thus converted into common salt. This reaction obviously gives hydrochloric acid a great advantage over other antiseptics, which introduce into the food a foreign substance, inimical by its very nature, in most cases, to the process of digestion.

\section{GYN $Æ C O L O G I C A L \quad$ NOTES.}

By ROBERT BARNES, M.D.,

Obstetric Physician, and Lecturer on Midwifery and Diseases of Women and Children, at St. Thomas's Hospital.

IV.-Sudden Death in Patients Suffering from Cancer. Patients suffering from cancer of the uterus or ovaries not unfrequently die suddenly. The causes of this event have not attracted much attention. The late.Dr. Todd (Clinical Lecturcs, Beale's edition) remarked that death may occur suddenly from malignant disease in the abdomen, as of the peritoneum. He was of opinion that cancerous matter passes suddenly into the circulation, causing prostration by poisoning, as in pyæmia.

There can be little doubt that, in some cases, where cancerous growth invades the walls of blood-vessels, portions may be detached and then swept into the circulation. I have, however, searched for these canceremboli without success in cases where the final symptoms seemed to point to pulmonary embolism; but in a woman suffering from encephaloid disease of the ovary and uterus, who recently died suddenly in St. Thomas's Hospital, my attention was fixed upon a condition which, I think, accounts for the catastrophe by a mechanism altogether different from embolism.

A woman aged 60 was admitted with the usual symptoms of cancerous cachexia of some duration. I found the pelvis filled with the morbid growth, involving uterus, vagina, rectum, and bladder, in one mass. Rest and good diet seemed to improve her condition ; but one day after being about she complained of difficulty of breathing, quickly became collapsed, and, without losing consciousness, died in a few minutes. 